\title{
DIRETRIZES PARA COMPREENSÃO DOS SILENCIAMENTOS NOS DISCURSOS PUBLICITÁRIOS BRASILEIROS: O SETOR AUTOMOTIVO
}

\author{
Guidelines for understanding the silences in Brazilian \\ advertising discourses: the automotive sector
}

\author{
Directrices para la comprehensión de los silenciamientos en los \\ discursos publicitarios brasileños: el sector automotriz
}

\author{
Rogério Luiz Covaleski \\ Universidade Federal de Pernambuco, Pernambuco, Brasil. \\ Doutor em Comunicação e Semiótica pela Pontifícia Universidade Católica de São Paulo. Coordenador \\ e professor permanente do Programa de Pós-graduação em Comunicação da Universidade Federal de \\ Pernambuco. \\ E-mail: rogerio@covaleski.com.br
}

\begin{abstract}
RESUMO Entre evidenciações e omissões, os discursos publicitários costumeiramente tendem a explicitar os argumentos favoráveis ao produto anunciado e a omitir tudo o que possa prejudicar a reputação deste. Esta investigação é de caráter teórico, mas também se sustenta na realidade mercadológica ao se apoiar em extensos dados que notabilizam o paradoxo de dizeres e silenciamentos nas publicidades de carros, com enfoque na realidade brasileira. A partir de revisão bibliográfica, cotejada com o levantamento de dados secundários, buscase compreender a lógica vigente em discursos hegemônicos confrontados com cenários de crise - sejam essas adversidades de ordem material ou de ordem simbólica. O artigo se apoia nas percepções sobre as retóricas do consumo a partir de Carrascoza, Casaqui e Nos Aldás; nas "contribuições" da publicidade para as práticas de consumo, com Coelho e Rocha; na discussão de ética e valores na sociedade de consumo, a partir de Baudrillard, Feenstra , Martín e Bauman. A pesquisa evidencia o hiato que há entre os dizeres e os silenciamentos nos discursos publicitários brasileiros do setor automotivo.
\end{abstract}

PALAVRAS-CHAVE Publicidade, Discurso, Silenciamentos, Setor automotivo, Brasil.

ABSTRACT Between disclosure and omissions, advertisers' speeches customarily tend to explain the arguments in favor of the advertised product and omit anything that might harm the reputation of that product. The research has a theoretical feature, but it is also based on the commercial reality, relying on extensive data that distinguishes the paradox of sayings and silences in advertising cars, focusing on the reality of Brazil. From literature review, compared to a collection of secondary data, the aim is to understand the prevailing logic in hegemonic discourses faced with crisis scenarios - whether these adversities are related to the material or to the symbolic order. The article is based on perceptions of the rhetorics of consumption of Carrascoza, Casaqui and Nos Aldás; the "contributions" of advertising for consumer practices, of Coelho and Rocha; and discussion of ethics and values in consumption society of Baudrillard, Feenstra, Martín and Bauman. The research highlights the gap between the words and the silencings in the Brazilian advertising discourses of the automotive sector.

KEYWORDS Advertising, Speech, Silences, Automotive sector, Brazil.

RESUMEN Entre evidencias y omisiones, los discursos publicitarios suelen tender a explicitar los argumentos favorables al producto anunciado y a omitir todo lo que pueda perjudicar la reputación de éste. Esta investigación es de carácter teórico, pero también se sostiene en la realidad mercadológica al apoyarse en extensos datos que destacan la paradoja de dichos y silenciamientos en las publicidades de coches, con enfoque en la realidad brasileña. Desde 
revisión bibliográfica, cotejada con el levantamiento de datos secundarios, se busca comprender la lógica vigente en discursos hegemónicos ante escenarios de crisis - sean esas adversidades de orden material o simbólico. El artículo se apoya en las percepciones sobre las retóricas del consumo a partir de Carrascoza, Casaqui y Nos Aldás; en las "contribuciones" de la publicidad para las prácticas de consumo, con Coelho y Rocha; en la discusión de ética y valores en la sociedad de consumo, desde Baudrillard, Feenstra, Martín y Bauman. Se evidencia el hiato que hay entre dichos y silenciamientos en los discursos publicitarios brasileños del sector automotriz.

PALABRAS CLAVE Publicidad, Discurso, Silenciamientos, Sector automotriz, Brasil.

\section{INTRODUÇÃO}

Este estudo propõe realizar uma reflexão sobre regimes de visibilidade e invisibilidade presentes nos discursos publicitários do segmento automotivo brasileiro. Entre evidenciações e omissões, as narrativas da publicidade costumeiramente tendem a explicitar os argumentos favoráveis ao produto anunciado e a omitir tudo o que possa prejudicar a reputação deste. Ao observar um palco de frequentes encenações discursivas, o artigo procura apresentar e refletir sobre algumas das evidentes divergências existentes em discursos publicitários, sobretudo em campanhas de automóveis. A reflexão é de caráter teórico, mas também se sustenta na realidade mercadológica ao se apoiar em extensos dados que notabilizam o paradoxo de dizeres e silenciamentos nas publicidades de carros, com enfoque na realidade do Brasil - país que detém posições invejáveis, tanto de viés positivo como negativo, em variados aspectos relacionados ao segmento automobilístico. A partir de revisão bibliográfica, cotejada com o levantamento de dados secundários, a pesquisa busca compreender a lógica vigente em discursos hegemônicos em cenários de crise - sejam essas adversidades de ordem material ou simbólica. A reflexão se estrutura nas retóricas do consumo, a partir de Carrascoza (2014a, 2014b), Casaqui (2009) e Nos Aldás (2007); nas “contribuições” da publicidade para as práticas de consumo, com Coelho (2003) e Rocha (2010); na discussão de ética e valores na sociedade de consumo, a partir de Baudrillard (2014), Feenstra (2014), Martín (2008) e Bauman (2014); e, por fim, analisa o cenário discursivo do setor automotivo na realidade brasileira.

\section{AS RETÓRICAS DO CONSUMO: ENTRE DIZERES E NÃO DIZERES}

$\mathrm{O}$ ato de consumir, contemporaneamente muito associado à ação individual e à subjetividade, promove o esgarçamento do conceito de retórica do consumo - a retórica constituída por elementos do discurso publicitário de indução ao consumo. A partir da compreensão de Baudrillard (2014), tal retórica é produzida por meio de um sistema de significação instigado pela indústria cultural, que contempla em sua abrangência a publicidade. Como aponta Baccega (2014, p. 63), "por um recente processo de publicização, as empresas adotam novas táticas discursivas de comunicação para divulgar suas marcas, mimetizando formatos midiáticos, sobretudo na internet, e mobilizando, dessa forma, seus recursos retóricos”, tal qual se faz notar no processo de hibridização da publicidade, com narrativas que, concomitantemente, persuadem, entretêm e interagem - constituindo, por si mesmas, novos produtos midiáticos (COVALESKI, 2015) - estabelecendo revisões conceituais da publicidade estandardizada. Mas, ressalte-se, que na atualidade coexistem 
o que se convenciona chamar de "publicidade tradicional" com novas configurações de discursos persuasivos que, em geral, promovem interação de marcas e consumidores, indo muito além das possibilidades propiciadas pelos meios massivos. Como define Casaqui (2009, p. 295), "a publicidade, em sentido amplo e no contexto da sociedade de consumo, é um fenômeno que se dissemina pela produção cultural contemporânea, como no cinema, no jornalismo, no esporte, na mídia de maneira geral, em espaços públicos e privados”.

O cotidiano do indivíduo contemporâneo é perpassado pelo sistema midiático - e parece haver poucas chances de evitá-lo. Como afirma Carrascoza (2014b, p. 8), tal sistema funciona como um "universo que incorpora o território material e simbólico de todos os meios de comunicação de massa e suas ramificações hibridizantes, está, a toda hora, e em todo lugar, na vida do indivíduo”. Evidencia, portanto, um indiscutível poderio que a publicidade impõe aos indivíduos nessa arena de tramas discursivas. Ainda segundo o autor, para partilharem de um mundo imaginário com seus públicos, as marcas devem investir em narrativas que construam valores materiais e simbólicos que ampliem as conexões afetivas e sensoriais com suas audiências. Mas, à margem do que se opta por dar visibilidade com seus dizeres, há um sombreamento - ou um total obscurecimento - do que se escolhe omitir em seus não dizeres, em seus silenciamentos:

1) pela impossibilidade natural de serem ditos uma vez que, sem seu lugar, algo já o foi e 2) pela estratégia discursiva adotada por seu enunciador, que privilegia determinados ditos, em detrimento de outros que não lhe convém mover por diversos motivos - o principal deles, certamente, porque não promovem tão bem a mercadoria anunciada, segundo a sua concepção, quanto os dizeres escolhidos (CARRASCOZA, 2014a, p. 107).

Privilegiar vantagens e omitir desvantagens é, portanto, uma recorrente estratégia discursiva da publicidade, quando se opta por dar visibilidade às qualidades do produto anunciado em detrimento de suas deficiências, completamente silenciadas.

Nesse sentido, vale ressaltar as contribuições do conceito de discurso como critério teórico para o estudo das representações publicitárias que, conforme Nos Aldás (2007, p. 145), são:

sobrepasar el límite de la frase; ir más allá del límite de la lengua (como sistema); estudiar las situaciones comunicativas y los discursos en su contexto, y, por lo tanto, considerar la interpretación y la interacción como bases de la comunicación publicitaria (desde la asunción de que cada receptor - en su individualidad - interpreta y reacciona ante la publicidad de diferentes modos y que los procesos comunicativos no son lineales sino interactivos); $\mathrm{y}$, por último, este concepto abarca la variedad y heterogeneidad de elementos expresivos que constituyen la publicidad en lugar de limitarse a sus sistemas verbales. De esta forma, las aproximaciones discursivas permiten estudiar cualquier manifestación publicitaria.

Tendo em vista tais pressupostos relacionados à retórica do consumo, e aos seus dizeres e não dizeres, segue-se à reflexão sobre o eventual papel cumprido pelo sistema publicitário nas práticas de consumo. 


\section{A “CONTRIBUIÇÃO” DO SISTEMA PUBLICITÁRIO PARA AS PRÁTICAS DE CONSUMO}

Diante da conjectura de o sistema publicitário se impor sobre o consumidor para além da mera constituição de um universo imaginário que o motive a adquirir um bem, e supondo que esse sistema gere um nível de interação que aja diretamente sobre o consumidor, como defende Coelho (2003, p. 39), a interação fomentada pelo sistema significa que o "corpo do consumidor passou a ser encarado como algo maleável, flexível, passível de mudança, como um objeto desprovido de vontade própria”. Considerando uma ideologia burguesa, o sistema publicitário propõe uma visão de mundo em que se constroem padrões e estereótipos, e impõe, inclusive, corpos coisificados, transformados em objetos.

Olhamos para nossos corpos procurando detectar o que falta para eles se transformarem em corpos idênticos ao corpo padrão, isto é, o corpo mostrado nas peças publicitárias: preocupamo-nos com a forma do corpo, com seu design, assim como com a sua embalagem (roupas, calçados etc.) (COELHO, 2003, p. 39).

Essa lógica sugere, também, que muitos dos bens consumidos sejam mais do que acessórios dos corpos dos consumidores, sejam propriamente extensões de cada indivíduo. Cada vez mais se aprimoram as características de produtos e serviços dentro de uma concepção tailor-made. A publicidade viceja o ato de consumir, por vezes, para além das capacidades do produto, fazendo prevalecer o objeto imerso em fábulas e imagens, como propõe Everardo Rocha (2010, p. 84):

De fato, o domínio do consumo é aquele no qual os homens e objetos são postos em contato. É pelo consumo e em seu interior que algumas das mais humanas das práticas encontram espaço de realização. O domínio do consumo é o da compra, da venda, das escolhas, dos negócios. E por excelência, um “negócio” humano. Nele, a palavra fundamental é a troca. Homens, objetos, valores e dádivas são trocados, adquiridos e retribuídos. Na esfera do consumo homens e objetos adquirem sentido, produzem significações e distinções sociais.

Distinções sociais essas muito evidenciadas em discursos publicitários que procuram deixar claro com quem estão se pondo em diálogo e de quem desejam atenção. Diferenças que se fazem notórias na estética, na linguagem, na forma de tratamento e no próprio casting escolhido para a narrativa explicitar qual perfil de consumidor se enquadra no públicoalvo desejado. Constituem operações classificatórias. Segmentações em um palco de diferenças, como entende Rocha (2010, p. 84), “objetos que fazem a presença e/ou ausência de identidade, visões de mundo, estilos de vida”. Dentre uma variedade de bens, no recorte de observação a que este artigo se propõe, os automóveis, sobretudo, não são consumidos de forma neutra, "eles trazem um universo de distinções", como reitera Rocha (2010, p. 84-85). Ao ser consumido, "o objeto se completa na sua vocação classificatória” (ROCHA, 2010, p. 85). A aquisição em si já é suficiente para classificar o consumidor, enquadrando-o material e simbolicamente com os mesmos atributos que o discurso persuasivo empregou na divulgação do produto. Rocha (2010, p. 85) arremata:

Da multiplicidade, serialidade e indistinção do seu produzir à particularidade, singularidade e peculiaridade do seu consumir. 
Da dura pragmática da produção à alegre ilusão da sua posse o objeto cumpre seu percurso em domínios distintos.

Mas seria possível supor uma comunicação publicitária destituída de seu viés persuasivo e instituidora de tantas distinções sociais? Para Ferrer (1997, p. 343), sem persuasão não há comunicação. Acredita o autor que há um código primário e natural de necessidades aspiracionais e indivisível da satisfação: "al margen de cualquier tipo de renunciación o código, la persuasión será siempre un tributo del lenguaje, independientemente del sí o del no. O de lo justo y lo injusto. O de sus amalgamas”. Ferrer esclarece, ainda, que é sabido que vivemos em uma sociedade dominada por desejos e gostos, que nos leva a nos satisfazer por meio de bens materiais. E afirma que bens como o automóvel desequilibram qualquer análise de preferência e de atendimento das necessidades básicas de consumo declaradas pelos indivíduos expostos aos efeitos discursivos da publicidade.

\section{ÉTICA E VALORES NA SOCIEDADE DE CONSUMO}

Dando continuidade à reflexão, ainda sob o prisma das distinções provocadas pelos discursos publicitários, mas agora também à luz da "revolução do bem-estar" proposta por Baudrillard (2014), a fim de se destacar questões de ordem ética e de valores no contexto da sociedade de consumo.

Para o filósofo e sociólogo francês - um dos que melhor diagnosticou as questões do mal-estar dos indivíduos contemporâneos em razão de impactos causados pela comunicação e pela mídia na sociedade e na cultura -, a busca incessante pelo bem-estar está associada ao mito burguês da felicidade e da igualdade. Segundo o autor (BAUDRILLARD, 2014, p. 40),

el principio democrático se transfiere pues de una igualdad real, de las capacidades, de las responsabilidades, de las oportunidades sociales, de la felicidad (en el sentido pleno del término) a una igualdad ante el Objeto y otros signos evidentes del éxito social y de la felicidad.

Em sua visão crítica, Baudrillard afirma que se trata da "democracia" da posição social, podendo ser também representada como uma democracia da televisão, do automóvel e de todo bem de consumo representativo. Trata-se de uma democracia que aparenta normalidade e concretude, mas se apresenta repleta de contradições e desigualdades sociais. Mais do que isso, segue uma ideologia nefasta e na qual a igualdade e a felicidade são conquistas impossíveis de se alcançar.

Para Hellín (2007), não há como negar que as marcas e suas hierarquias de valores ocupam um lugar de protagonismo no desenvolvimento social e econômico da sociedade. Mas, em uma estrutura social que, ao mesmo tempo, enaltece as necessidades, o pertencimento, a autoestima e a autorrealização.

Ao refletir sobre discursos que fomentam estereótipos e que reforçam o destino pensado para cada um dos nichos de público eventualmente vilipendiados pela publicidade, seguindo uma estratégia discursiva reducionista e simplificadora, Feenstra (2014) afirma que deve haver rigor por parte de autoridades reguladoras quanto aos limites abusivos das campanhas publicitárias. Para o autor (FEENSTRA, 2014, p. 63), 
Este tipo de exigencias y preocupaciones se fundamentan precisamente en la idea de que la publicidad no solo tiene una responsabilidad técnica y legal con respecto a la sociedad, sino que también tiene una evidente dimensión moral debido a su alto nivel de influencia que posee en la configuración de valores.

Com as mesmas preocupações, Martín (2008) afirma que a sociedade está diante de uma forte crise de valores tradicionais, além de sofrer influência de modelos culturais hegemônicos que impõem suas regras e seus valores. Com efeito, isso tem gerado o surgimento de um quadro de valores contraditórios. O autor esclarece que, enquanto no âmbito profissional e econômico se defendem valores como competitividade, eficiência, produtividade, agressividade, globalização e busca pelo próprio lucro, em outros âmbitos, nos quais as relações humanas prevalecem, defende-se a solidariedade, a empatia, a cooperação, o altruísmo. Para Martín (2008, p. 45),

Esta dualidad de motivaciones son experimentadas por los seres humanos como individuos y por la sociedad como grupo de personas, y según se incline la balanza hacia un lado o hacia el otro, nos encontramos con grupos sociales o sociedades economicistas, cuya finalidad será aumentar cada vez más el capital económico, en espera de encontrar el bienestar, o con sociedades que se inclinan por mejorar las redes comunicativas existentes y por poner en práctica las reglas de reciprocidad y confianza, en definitiva en mejorar su capital social.

Entretanto, o autor pondera que devemos ter ciência de que a vida em sociedade tem se deteriorado. Cada vez mais surgem condutas autodestrutivas, o que requer da sociedade um trabalho intenso para a retomada de normas sociais por meio de debates e discussões culturais.

Em linha semelhante de raciocínio, porém com olhar ainda mais pessimista, Bauman (2014) trabalha com presunções implícitas que têm sido aceitas como óbvias na sociedade contemporânea. Para o sociólogo polonês, há uma crença coletiva de que por meio do crescimento econômico todos os problemas da existência humana serão suplantados; que o incremento contínuo do consumo encurtará a busca pela felicidade e a satisfação de cada indivíduo; que a desigualdade entre os homens é natural, e aplacá-la traz mais prejuízos que benefícios a todos; que a competitividade constitui uma condição necessária e suficiente para se alcançar a justiça social.

Enfim, visões que somadas trazem um cenário sombrio e preocupante a respeito dos reflexos do discurso publicitário sobre o público, no que tange a seus dizeres e silenciamentos.

\section{DIZERES E SILENCIAMENTOS NOS DISCURSOS PUBLICITÁRIOS DO SETOR AUTOMOTIVO BRASILEIRO}

O segmento de veículos, incluindo peças e acessórios, movimentou no Brasil, em 2015, quase R $\$ 3,5$ bilhões em publicidade - o setor é o sétimo que mais investe, atrás de "comércio, varejo", "serviços ao consumidor", "mercado financeiro e seguros", "cultura, lazer, esporte e turismo" e "farmacêutica”; e à frente de "alimentação", "bebidas” e "mídia”, no ranking dos 10 setores com maior investimento publicitário no país, em um total de pouco mais de $\mathrm{R} \$ 60$ bilhões ao longo do primeiro semestre de 2015, segundo o Ibope Media. 
Considerando a relevância material e simbólica do setor, a pesquisa em curso se propõe a trazer à tona uma série de dados indicativos sobre os silenciamentos existentes nos discursos publicitários da indústria automotiva. Leve-se em conta que os dizeres presentes nesses mesmos discursos, e que formam parte da identidade discursiva dos anunciantes do segmento, presumivelmente, são conhecidos e, por vezes, enquadrados como discursos-clichê. Discursos que, em geral, se mantêm imutáveis por anos e para tantos dos atores desse cenário. Assim, como afirma Hoff (2012, p. 151), por analogia sobre a questão da "diferença", "nos processos comunicacionais, podemos avaliar, o igual - a identidade - que promove a estabilidade, a diferença tende a desestabilizar, a promover a tensão, dispersão ou ruptura", e tem o que se enquadra como "diferente" em termos discursivos nesse setor, que tende a ser a exceção à regra - o que no âmbito dessa observação o torna descartável, considerando a opção de atenção aos discursos hegemônicos e prevalentes.

Ressalte-se, ainda, que os discursos “dissonantes” que pregam valores positivos não constituem propriamente novidade, como observa Maria Eduarda Rocha (2004, p. 61-62):

Na verdade, a associação das marcas a "valores” não é nova. O que mudou foi o conteúdo predominante nesses "valores", cada vez menos intrínsecos ao usufruto funcional e distintivo do produto. Enquanto, até os anos 1980, o "status" e a "tecnologia" ocupavam esse lugar, nos anos 1990 a "responsabilidade social" e a "qualidade de vida" tornaram-se o centro das estratégias narrativas mais recorrentes na publicidade brasileira de construção de grandes marcas, especialmente as dos setores bancário e automobilístico.

Para fins de observação de possíveis silenciamentos dos discursos publicitários do setor automotivo brasileiro, uma série de dados de fontes secundárias serão apresentados, subdivididos em eixos temáticos - sempre no âmbito brasileiro, mas, eventualmente, parametrizando com realidades internacionais: a violência do trânsito, a crise econômica e a queda nas vendas, a diminuição nos investimentos publicitários, as queixas dos consumidores, os congestionamentos recordes.

\section{A violência do trânsito}

As estatísticas nacionais de acidentes de trânsito, segundo o Ministério da Saúde do Brasil, indicam que houve 43.075 óbitos e 201.000 feridos hospitalizados em 2014. Outra fonte, partindo de dados relacionados ao acionamento do Seguro DPVAT, indica que foram emitidas, no mesmo ano, 52.200 indenizações por morte e 596.000 por invalidez. Em um levantamento do DataSUS, ao longo de 10 anos, as mortes decorrentes de acidentes de trânsito no Brasil saltaram de 35.105, em 2004, para 43.075, em 2014 - um crescimento de $22,7 \%$. O Brasil é o quinto país no mundo em mortes por acidentes no trânsito.

\section{A crise econômica e a queda nas vendas}

Uma rápida busca na internet por notícias sobre o desempenho do segmento automotivo brasileiro, em 2015, é suficiente para evidenciar a grave crise por que passa a indústria automotiva do país: 
"Setor automobilístico pode desacelerar ainda mais em 2016"1; "Crise no setor automotivo já deixou 12.000 desempregados"2; "Crise do setor automobilístico no Brasil repercute em Frankfurt";; "Crise no setor automotivo não afugenta montadoras"4; "Caos automotivo: em meio à crise, montadoras massacram concessionárias”;; "Em crise, mercado automotivo brasileiro encolhe" 6 ; "Mercado encolheu 27,6\% este ano" .

Em um ranking de vendas (Tabela 1) das 10 marcas mais comercializadas no mercado brasileiro, de janeiro a setembro de 2015, somente uma aferiu desempenho positivo em relação ao exercício anterior - caso da Honda, que com o lançamento do HR-V, conseguiu recorde de vendas no país, fazendo de seu SUV compacto uma exceção ao que ocorreu no mercado, e alavancando as vendas gerais da marca, com $17,42 \%$ de crescimento. Todas as demais marcas sofreram sensíveis quedas nas vendas, atingindo, sobretudo, as três montadoras com maior volume de vendas - todas com desempenhos negativos acima dos 30\% em relação ao ano anterior.

Tabela 1. Ranking de vendas.

\begin{tabular}{|c|c|c|c|}
\hline \multicolumn{4}{|c|}{ AS 10 MARCAS MAIS VENDIDAS NO BRASIL } \\
\hline POSIÇÃO & MONTADORA & EMPLACAMENTOS & DESEMPENHO \\
\hline $1^{\mathrm{a}}$ & FIAT & 342.717 & $-33,62 \%$ \\
\hline $2^{\mathrm{a}}$ & GENERAL MOTORS & 289.018 & $-30,85 \%$ \\
\hline 3a & VOLKSWAGEN & 283.207 & $-32,97 \%$ \\
\hline $4^{\mathrm{a}}$ & FORD & 200.844 & $-7,08 \%$ \\
\hline 5 a & HYUNDAI & 151.653 & $-10,34 \%$ \\
\hline $6 \underline{a}$ & RENAULT & 134.779 & $-19,84 \%$ \\
\hline $7 \underline{a}$ & TOYOTA & 132.559 & $-2,52 \%$ \\
\hline $8^{a}$ & HONDA & 112.551 & $17,42 \%$ \\
\hline 9a & NISSAN & 46.468 & $-6,23 \%$ \\
\hline $10^{\mathrm{a}}$ & MITSUBISHI & 32.509 & $-25,22 \%$ \\
\hline
\end{tabular}

Fonte: Automotive Business (janeiro a setembro de 2015).

No cenário internacional, a retração nas vendas de automóveis também foi mais sentida no Brasil, onde houve uma diminuição de mais de um quarto das vendas - ou, precisamente, $-25,59 \%$. Dos demais países que compõem o ranking dos 10 maiores mercados de automóveis (Tabela 2), somente o Japão apresentou desempenho negativo além

1. Publicado no portal G1 em 7 jan. 2016. Disponível em: <https://goo.gl/GvWmn9>. Acesso em: 6 fev. 2018.

2. Matéria publicada no portal da revista Exame em 7 maio 2015. Disponível em: <https:// goo.gl/h9PKvS>. Acesso em: 6 fev. 2018.

3. Publicado na versão on-line do jornal Folha de S.Paulo, em 17 set. 2015. Disponível em: <https://goo.gl/c6t18y>. Acesso em: 6 fev. 2018.

4. Publicado no portal de notícias da revista Carta Capital, em 13 mar. 2015. Disponível em: $<$ https://goo.gl/xd1Doh>. Acesso em: 6. fev. 2018.

5. Reportagem publicada no portal de notícias do Jornal do Brasil, em 7 jan. 2016. Disponível em: <https://goo.gl/4udP9C>. Acesso em: 6 fev. 2018.

6. Publicado na versão on-line do jornal Gazeta do Povo, em 4 nov. 2014. Disponível em: <https://goo.gl/7nA9J5>. Acesso em: 6 fev. 2018.

7. Matéria publicada no blog $O$ mundo em movimento, em 2 maio 2016. Disponível em: <https://goo.gl/5LMi2p>. Acesso em: 6 fev. 2018. 
do Brasil, mas com resultados menos dramáticos - -9,46\%. Com esse desempenho, o mercado brasileiro caiu para a sétima colocação no ranking mundial de venda de carros. Em 2014, era o quarto maior vendedor. Em um comparativo com os países de economia emergente como o Brasil neste ranking, China e Índia aferiram resultados positivos. O número de veículos emplacados em nosso país beirou 3,5 milhões de unidades.

Tabela 2. Ranking mundial de vendas.

\begin{tabular}{|c|c|c|c|}
\hline \multicolumn{4}{|c|}{ VENDAS MUNDIAIS DE AUTOMÓVEIS } \\
\hline POSIÇÃO & PAÍS & EMPLACAMENTOS & DESEMPENHO \\
\hline $1^{a}$ & CHINA & 22.358 .140 & $6,44 \%$ \\
\hline $2^{\mathrm{a}}$ & ESTADOS UNIDOS & 17.469 .043 & $5,75 \%$ \\
\hline 3a & JAPÃO & 4.975 .791 & $-9,46 \%$ \\
\hline $4^{\mathrm{a}}$ & ALEMANHA & 3.439 .767 & $5,47 \%$ \\
\hline $5^{\mathrm{a}}$ & ÍNDIA & 3.060 .671 & $4,81 \%$ \\
\hline 6 a & GRÃ-BRETANHA & 3.005 .333 & $7,41 \%$ \\
\hline $7 \underline{a}$ & BRASIL & 2.476 .981 & $-25,59 \%$ \\
\hline $8 \underline{a}$ & FRANÇA & 2.294 .265 & $5,96 \%$ \\
\hline 9a & CANADÁ & 1.901 .025 & $2,59 \%$ \\
\hline $10^{a}$ & COREIA DO SUL & 1.799 .813 & $10,91 \%$ \\
\hline
\end{tabular}

Fonte: Jato Dynamics (2015).

\section{A diminuição nos investimentos publicitários}

No levantamento dos 30 maiores anunciantes do país seis são montadoras - talvez não por coincidência, exatamente as seis que mais venderam automóveis e comerciais leves no mercado brasileiro em 2014. Fiat, General Motors, Volkswagen, Hyundai, Ford e Renault ocuparam a $11^{\mathrm{a}}, 14^{\mathrm{a}}, 16^{\mathrm{a}}, 21^{\mathrm{a}}, 26^{\mathrm{a}}$ e $29^{\mathrm{a}}$ posições do ranking, respectivamente (Tabela 3). Contudo, mesmo apresentando volumes significativos de investimento em mídia, os montantes apresentaram decréscimo no último ano, em relação a 2014 - situação inversa à comparação entre os dois anos anteriores.

Tabela 3. Histórico de investimento publicitário no ranking dos maiores anunciantes.

\begin{tabular}{ccccc}
\hline \multicolumn{5}{c}{ MAIORES ANUNCIANTES DO BRASIL } \\
\hline POSIÇÃO & MONTADORA & $\mathbf{2 0 1 5}$ & $\mathbf{2 0 1 4}$ & $\mathbf{2 0 1 3}$ \\
\hline $11^{\underline{a}}$ & FIAT & 994.926 & 1.170 .070 & 1.092 .100 \\
\hline $14^{\underline{a}}$ & GENERAL MOTORS & 823.904 & 1.085 .379 & 955.020 \\
\hline $16^{\underline{a}}$ & VOLKSWAGEN & 784.898 & 1.015 .011 & 1.206 .400 \\
\hline $21^{\underline{a}}$ & HYUNDAI & $\mathrm{n} / \mathrm{d}$ & 846.200 & 665.500 \\
\hline $26^{\underline{a}}$ & FORD & $\mathrm{n} / \mathrm{d}$ & 755.100 & 692.600 \\
\hline $29^{\underline{a}}$ & RENAULT & $\mathrm{n} / \mathrm{d}$ & 646.800 & 949.500 \\
\hline
\end{tabular}

Fonte: Kantar Ibope (dezembro 2015) - em R $\$$ (000)

Em outra perspectiva, faz-se interessante observar que há uma inversão no ranking posterior (Tabela 4), que apura qual o investimento em publicidade de cada marca ao se confrontar com o número de veículos emplacados no mesmo período. Assim, pode-se notar o esforço comunicacional empregado por marcas com menor participação de mercado, que investem muito mais em publicidade para cada unidade vendida. 
Tabela 4. Investimento e emplacamentos.

INVESTIMENTO EM PUBLICIDADE VS. EMPLACAMENTOS EM 2014

\begin{tabular}{ccc}
\hline POSIÇÃO & MONTADORA & GASTO POR UNIDADE VENDIDA \\
\hline $1^{\text {ae }}$ & HYUNDAI & $\mathrm{R} \$ 3.557,00$ \\
\hline $2^{\underline{a}}$ & RENAULT & $\mathrm{R} \$ 2.727,00$ \\
\hline $3^{\underline{a}}$ & FORD & $\mathrm{R} \$ 2.303,00$ \\
\hline $4^{\mathrm{a}}$ & GENERAL MOTORS & $\mathrm{R} \$ 1.875,00$ \\
\hline $5^{\underline{a}}$ & VOLKSWAGEN & $\mathrm{R} \$ 1.760,00$ \\
\hline $6^{\underline{a}}$ & FIAT & $\mathrm{R} \$ 1.675,00$ \\
\hline
\end{tabular}

Fonte: Agência AutoData e Ibope Monitor (2014).

\section{As queixas dos consumidores}

O setor automotivo representou 8,3\% das queixas de consumidores julgadas pelo Conselho Nacional de Autorregulamentação Publicitária (CONAR), em 2015 (Quadro 1), o que representa somente 19 casos. Na maior parte deles, em 13, houve recomendação de arquivamento do caso, não gerando nenhuma repercussão para os anunciantes. Em cinco casos, pediu-se alterações no conteúdo da mensagem veiculada, sendo que em dois desses casos, advertências foram geradas às empresas. Em um único caso no último ano, houve recomendação de sustação e aplicação de advertência ao anunciante.

A maior parte dos enquadramentos diz respeito à "veracidade" da mensagem, em um total de 12 casos; "respeitabilidade", "responsabilidade social" e "apresentação verdadeira" foram enquadramentos presentes em dois casos cada, enquanto questões envolvendo "crianças e adolescentes” teve apenas um caso julgado. As motivações que levaram consumidores e marcas concorrentes a acionarem o CONAR variam de publicidade enganosa a machismo, passando por imprecisão das informações e direção perigosa, concorrência antiética, informações incompletas ou a falta de informações essenciais, e até por conta do medo que poderiam causar.

Quadro 1. Queixas de consumidores e anunciantes.

\begin{tabular}{|l|c|c|c|}
\hline \multicolumn{5}{|c|}{ CASOS JULGADOS PELO CONAR EM 2015 - SETOR AUTOMOTIVo } \\
\hline MONTADORA & ENQUADRAMENTO & MOTIVAÇÃo & DECISÃo \\
\hline CHEVROLET & Veracidade & Enganosa & Alteração \\
\hline CHEVROLET & Veracidade & Carência de veracidade & Arquivamento \\
\hline CHEVROLET & Veracidade & Concorrência antiética & Arquivamento \\
\hline FIAT & Veracidade & Imprecisão das informações & Arquivamento \\
\hline FIAT & Veracidade & Informação contestada & Alteração \\
\hline FIAT & Veracidade & Enganosa & Arquivamento \\
\hline FIAT & Apresentação verdadeira & Enganosa & Alteração \\
\hline FIAT & Veracidade & Imprecisão das informações & $\begin{array}{c}\text { Alteração e } \\
\text { advertência }\end{array}$ \\
\hline FORD & Apresentação verdadeira & Imagem contestada & Arquivamento \\
\hline HYUNDAI & Respeitabilidade & Machismo & Arquivamento \\
\hline HYUNDAI & Veracidade & Imprecisão das informações & Arquivamento \\
\hline HYUNDAI & Veracidade & Enganosa & $\begin{array}{c}\text { Alteração e } \\
\text { advertência }\end{array}$ \\
\hline NISSAN & & & Arquivamento \\
\hline
\end{tabular}


Quadro 1. Continuação.

\begin{tabular}{|l|c|c|c|}
\hline \multicolumn{4}{|c|}{ CASOS JULGADOS PELO CONAR EM 2015 - SETOR AUTOMOTIVO } \\
\hline MONTADORA & ENQUADRAMENTO & MOTIVAÇÃo & DECISÃo \\
\hline RENAULT & Veracidade & $\begin{array}{c}\text { Falta de informação } \\
\text { essencial }\end{array}$ & $\begin{array}{c}\text { Sustação e } \\
\text { advertência }\end{array}$ \\
\hline RENAULT & Veracidade & Imprecisão das informações & Arquivamento \\
\hline RENAULT & Veracidade & Informações incompletas & Arquivamento \\
\hline TOYOTA & Responsabilidade social & Direção perigosa & Arquivamento \\
\hline VOLKSWAGEN & Crianças e adolescentes & Medo & Arquivamento \\
\hline VOLKSWAGEN & Responsabilidade social & Direção perigosa & Arquivamento \\
\hline
\end{tabular}

Fonte: CONAR (2015)

\section{Os recordes de congestionamentos}

Os congestionamentos de trânsito vêm aumentando no âmbito global. Um estudo anual sobre o trânsito no mundo, em cidades com mais de 800 mil habitantes, sintetiza essa tendência a partir de dados fornecidos e tabulados por uma empresa de navegação automotiva (Tabela 5). O levantamento aponta que, dentre as 10 cidades mais congestionadas do mundo, três são brasileiras: Rio de Janeiro, Salvador e Recife.

Tabela 5. Ranking de congestionamento.

\begin{tabular}{|c|c|c|c|}
\hline \multicolumn{4}{|c|}{ AS CIDADES MAIS CONGESTIONADAS DO MUNDO } \\
\hline COLOCAÇÃO & CIDADE & PAÍs & $\begin{array}{l}\text { TEMPO ADICIONAL } \\
\text { DE PERCURSO }\end{array}$ \\
\hline $1^{\underline{a}}$ & Cidade do México & México & $59 \%$ \\
\hline $2^{a}$ & Bangcoc & Tailândia & $57 \%$ \\
\hline 3 a & Istambul & Turquia & $50 \%$ \\
\hline $4^{\mathrm{a}}$ & Rio de Janeiro & Brasil & $47 \%$ \\
\hline 5 & Moscou & Rússia & $44 \%$ \\
\hline 6a & Bucareste & Romênia & $43 \%$ \\
\hline $7 \mathrm{a}$ & Salvador & Brasil & $43 \%$ \\
\hline $8^{\mathrm{a}}$ & Recife & Brasil & $43 \%$ \\
\hline 9a & Chengdu & China & $41 \%$ \\
\hline $10^{a}$ & Los Angeles & Estados Unidos & $41 \%$ \\
\hline
\end{tabular}

Fonte: TomTom Trafic Index (2016).

A avaliação leva em conta o tempo extra, em dados percentuais, que motoristas levam para percorrer trajetos em relação ao que seria necessário em momentos nos quais não é registrada lentidão.

\section{ALGUMAS CONSIDERAÇÕES POSSÍVEIS}

A partir da reflexão teórica proposta e diante dos dados expostos quanto a temas invariavelmente silenciados pelos discursos publicitários do setor automotivo, vale ressaltar, à guisa de conclusão do artigo:

- A violência do trânsito no Brasil coloca o país na quinta colocação mundial em mortes envolvendo acidentes automobilísticos, ainda assim, muitas narrativas publicitárias de carros anunciam de forma enfática a velocidade do automóvel, o torque do motor, a força do arranque, a similaridade aos carros de corrida, entre outros 
diferenciais que estimulam a não observância das leis de trânsito ou mesmo das técnicas de condução segura.

- A crise econômica que afetou o país, sobretudo a partir de 2014, acelerou a perda de competitividade da indústria, gerando demissões, greves, perda de incentivos fiscais, e resultou em uma acentuada queda nas vendas. Na média do mercado brasileiro, houve redução de um quarto entre os anos de 2014 e 2015. A marca líder de mercado chegou a perder quase um terço de suas vendas de um ano para o outro. Ainda assim, os valores para aquisição de automóveis praticados no Brasil estão, proporcionalmente, entre os mais altos do mundo, e mesmo em cenários de crise, as negociações, em geral, flexibilizam condições e prazos de pagamento, mas pouco abatem do custo total final para o consumidor.

- A diminuição nos investimentos publicitários tem se evidenciado na perda de posições das montadoras no ranking dos maiores anunciantes do país, o que não gera um efeito imediato sobre o consumidor e a sua decisão de compra. Contudo, os valores investidos por algumas marcas, principalmente aquelas que necessitam aumentar seu market share, sugerem quanto do valor final de aquisição do automóvel tem de valor investido em publicidade embutido no preço. Ainda assim, tais marcas, a título de maior visibilidade, optam por centrar esforços nas campanhas publicitárias que enaltecem qualidades extrínsecas ao produto em vez de beneficiar o público de forma direta com descontos nos preços praticados.

- As queixas dos consumidores, ao menos no se evidencia nas reclamações direcionadas ao órgão de autorregulamentação publicitária, dizem respeito mais aos dizeres propriamente - que apresentam alguma falha constitutiva ou induzem ao erro de interpretação - do que aos silenciamentos sobre os temas elencados nesta pesquisa. Ainda assim, o discernimento e a sensibilidade em uma parte crescente do público requisita das marcas novas posturas e responsabilidades discursivas, diante dos descompassos que se notam entre as narrativas publicitárias de automóveis e a realidade da mobilidade no país.

- Os congestionamentos recordes que afligem as maiores cidades do Brasil explicitam a incoerência de grande parte das campanhas publicitárias de carros no país. Ruas desertas, bem sinalizadas e em ótimo estado de conservação são elementos recorrentes nos filmes publicitários, mesmo que evidenciem uma realidade de desfrute do automóvel quase inalcançável pelo consumidor. Ainda assim, a maior parte das marcas insiste em criar narrativas que ignoram a inviabilidade de uso - tal qual demostram as respectivas publicidades - de boa parte dos recursos de desempenho e conforto que os carros supostamente contemplam.

Tendo em vista tais ponderações, presume-se que a pesquisa tenha evidenciado o hiato que há entre os dizeres e os silenciamentos nos discursos publicitários brasileiros do setor automotivo. Futuras investigações podem dar conta de confrontar outros temas silenciados nesses mesmos discursos, a fim de esclarecer que a reflexão aqui proposta não se esgota, mas que busca servir como ponto inicial de indagação das razões de manutenção desses modelos discursivos hegemônicos e, aparentemente, anacrônicos. 


\section{REFERÊNCIAS}

BACCEGA, M. A. Comunicação e consumo. In: CITELLI, A. et al. (Orgs.). Dicionário de Comunicação: escolas, teorias e autores. São Paulo: Contexto, 2014. p. 53-65.

BAUDRILLARD, J. La sociedad de consumo. Sus mitos, sus estructuras. Madrid: Siglo XXI, 2014

BAUMAN, Z. ¿La riqueza de unos pocos nos beneficia a todos? Barcelona: Paidós, 2014.

CARRASCOZA, J. A. Dizeres e silenciamentos na narrativa publicitária contemporânea. In: ATEM, G. N.; OLIVEIRA, T. M.; AZEVEDO, S. T. (Orgs.). Ciberpublicidade: discurso, experiência e consumo na cultura transmidiática. Rio de Janeiro: E-papers, 2014a. p. 107-119.

Estratégias criativas da publicidade: consumo e narrativa publicitária. São Paulo:

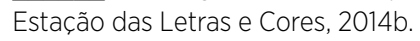

CASAQUI, V. Publicidade. In: MARCONDES FILHO, C. (Org.). Dicionário da Comunicação. São Paulo: Paulus, 2009. p. 291-296.

COELHO, C. N. P. Publicidade: é possivel escapar? São Paulo: Paulus, 2003.

COVALESKI, R. Cinema e publicidade: intertextos e hibridismos. Rio de Janeiro: Confraria do Vento, 2015.

FEENSTRA, R. A. Ética de la publicidad. Retos en la era digital. Madrid: Dykinson, 2014.

FERRER, E. El lenguaje de la publicidad. México: Tezontle, 1997.

HELLÍN, P. A. O. Publicidad y valores posmodernos. Madrid: Siranda, 2007.

HOFF, T. Produção de sentido e publicização do discurso da diferença na esfera do consumo. In: ROCHA, R. M.; CASAQUI, V. (Orgs.). Estéticas midiáticas e narrativas do consumo. Porto Alegre: Sulina, 2012. p. 145-161.

MARTÍN, L. R. Comunicar valores. Los viejos y nuevos valores de la sociedad de información y el conocimiento. In: MARTíN, L. R. (Org.). Publicidad y consumo. Nuevas modas, viejas causas y valores sociales. Sevilla: Comunicación Social, 2008. p. 42-63.

NOS ALDÁS, E. Lenguaje publicitario y discursos solidarios. Eficacia publicitaria, ceficacia cultural? Barcelona: Icaria, 2007.

ROCHA, E. Magia e capitalismo: um estudo antropológico da publicidade. São Paulo: Brasiliense, 2010.

ROCHA, M. E. M. A nova retórica do grande capital: a publicidade brasileira entre o neoliberalismo e a democratização. Revista Comunicação, Mídia e Consumo, São Paulo, v. 1, n. 2, p. 50-76, ago. 2004. 